\title{
The Impact of the Observation Data Assimilation on Atmospheric Reanalyses over Tibetan Plateau and Western Yunnan-Guizhou Plateau
}

\author{
Xinghua Bao ${ }^{1, *(\mathbb{D}}$, Fuqing Zhang ${ }^{2}$, Yang Zhao ${ }^{1} \mathbb{( \mathbb { C }}$ and Yueli Chen ${ }^{1}$ \\ 1 State Key Laboratory of Severe Weather, Chinese Academy of Meteorological Sciences, Beijing 100081, China; \\ zhaoyang@cma.gov.cn (Y.Z.); chenyl@cma.gov.cn (Y.C.) \\ 2 Center for Advanced Data Assimilation and Predictability Techniques, and Department of Meteorology and \\ Atmospheric Science, The Pennsylvania State University, State College, PA 16802, USA; fzhang@psu.edu \\ * Correspondence: baoxh@cma.gov.cn; Tel.: +86-010-6840-9516
}

Citation: Bao, X.; Zhang, F.; Zhao, Y.; Chen, Y. The Impact of the Observation Data Assimilation on Atmospheric Reanalyses over Tibetan Plateau and Western Yunnan-Guizhou Plateau. Atmosphere 2021, 12, 38. https:// doi.org/10.3390/atmos12010038

Received: 7 November 2020 Accepted: 27 December 2020 Published: 30 December 2020

Publisher's Note: MDPI stays neutral with regard to jurisdictional clai$\mathrm{ms}$ in published maps and institutional affiliations.

Copyright: (C) 2020 by the authors. Licensee MDPI, Basel, Switzerland. This article is an open access article distributed under the terms and conditions of the Creative Commons Attribution (CC BY) license (https:// creativecommons.org/licenses/by/ $4.0 /)$.

\begin{abstract}
Three modern atmospheric reanalyses with different input observation data (NOAACIRES 20th Century Reanalysis (20CR), Japanese 55-year Reanalysis (JRA-55), and JRA-55C) were compared against the independent radiosonde observations over the Tibetan Plateau (TP) and the western Yunnan-Guizhou Plateau (YGP) from the China-Japan Meteorological Disaster Reduction Cooperation (JICA/Tibet) Center Project in the summer of 2018 to investigate the effects of the assimilation of the observation data on the quality and accuracy of the reanalyses in the troposphere. The results indicate that the mean biases and mean root-mean-square errors of horizontal wind, temperature, and specific humidity significantly decreased when comparing the 20CR reanalysis (assimilating only surface pressure) to the JRA-55C (assimilating conventional surface and upper-air observations) and the JRA-55 (assimilating conventional and satellite observations), and the bias spreads of these aboveground variables in JRA-55C and JRA-55 were cut to almost half of those observed in 20CR. However, the mean biases and uncertainties varied little from JRA-55C to JRA-55. This means that the assimilation of conventional observation data plays a vital role in the quality of reanalyses for the troposphere over these data-sparse plateaus. It was also found that the temperature and specific humidity near the ground over TP showed larger mean biases and bias spans than those over YGP, likely due to the sparser surface observation over TP.
\end{abstract}

Keywords: Tibetan Plateau; reanalysis data comparison; the impact of input observations

\section{Introduction}

The Tibetan Plateau (TP), the largest and highest plateau on earth, plays an essential role in the regional and even the global climate [1-6]. The Yunnan-Guizhou Plateau (YGP), located southeast of TP, also affects the climate and weather (e.g., Indian monsoon, precipitation) over Central Asia [7,8]. The use of observations alone is very limiting in climate and weather studies over these plateaus due to the spatial and temporal sparsity of the data. As a better choice, assimilation reanalyses, which combine the benefits of both forecast models and observations, have been frequently used in atmospheric science studies for TP regions [4,9-12].

The quality and performance of reanalysis datasets are related to many factors, such as the model structure, assumptions, and data assimilation methods, as well as the input observation data sources, etc. [13-16]. The quantity and quality of the observation data assimilated as part of the reanalyses and consisting of conventional and satellite data are major factors influencing the performance of reanalyses [16]. Reanalyses, especially in the stratosphere, are sensitive to changes in the number and type of input satellite observations [17-20]. The performance of various atmospheric reanalyses of TP regions has been assessed in previous studies [13,14,21-23]. It was found that updating the data assimilation 
systems, improving the quality, and increasing the amount of input observations have a positive effect on the quality of reanalysis data across these regions. The quality of almost all the reanalyses was improved following the updating of the satellite observing system at the end of 1998 [24,25]. Bao and Zhang [14] found that the quality of reanalysis over TP had improved significantly from the early period (1998) to the later period (2008 and 2015-2016) mainly due to the huge increase in the amount and quality of input satellite observations. They also note that the Japanese 55-year Reanalysis (JRA-55) [26], a global atmospheric reanalysis with a $\sim 55 \mathrm{~km}$ resolution led by the Japan Meteorological Agency (JMA), showed relatively better quality than other reanalyses in 1998 because the soundings collected in the field campaign were assimilated into the JRA reanalysis. With its use of conventional and satellite observation data assimilation, JRA-55 is one of the widely used modern atmospheric reanalysis products. It has been verified to have good quality over TP [14]. However, few studies have documented to what extent the assimilation of observation data affects the reanalysis products. The quantitative differences between reanalyses assimilating conventional data with and without satellite data over TP and YGP are still unknown.

The NOAA-CIRES 20th Century Reanalysis (20CR) [27], spanning 1851 to 2012, used an ensemble Kalman filter (EnKF) approach to assimilate only surface pressure. JRA-55 and 20CR essentially represent the reanalysis product performance with and without the assimilation of observation data, respectively. Additionally, JRA-55C [28], which uses the same data assimilation system as JRA-55 to assimilate only conventional surface and upper-air observations, can provide insights on the quality of reanalysis in the absence of satellite observations.

The China-Japan Meteorological Disaster Reduction Cooperation Research Center Project (JICA/Tibet Project [29]) deployed numerous radiosonde observations over TP and western YGP in the summer of 2008 (Figure 1). None of these sounding observations were introduced to any of the reanalyses. This dataset can thus be used to evaluate the sensitivity of reanalyses over TP and YGP according to different input observation sets. For this study, these different sets consist of (a) only surface pressures with the 20CR reanalysis, (b) only conventional observations with the JRA-55 reanalysis, and (c) both conventional and satellite data with JRA-55C. Moreover, the quality of reanalysis products over YGP is seldom discussed. It is also not very clear whether reanalysis products over YGP show better or worse performance compared with those over TP. The spatial density of conventional observation data also affects the quality of reanalyses. Reanalyses show different quality levels for regions with different data densities; for example, the root-meansquare errors (RMSEs) are lower for horizontal winds and relative humidity over data-rich Southern China, compared to those from the data-sparse TP [30]. This study is an extension of our earlier studies $[13,14]$. 


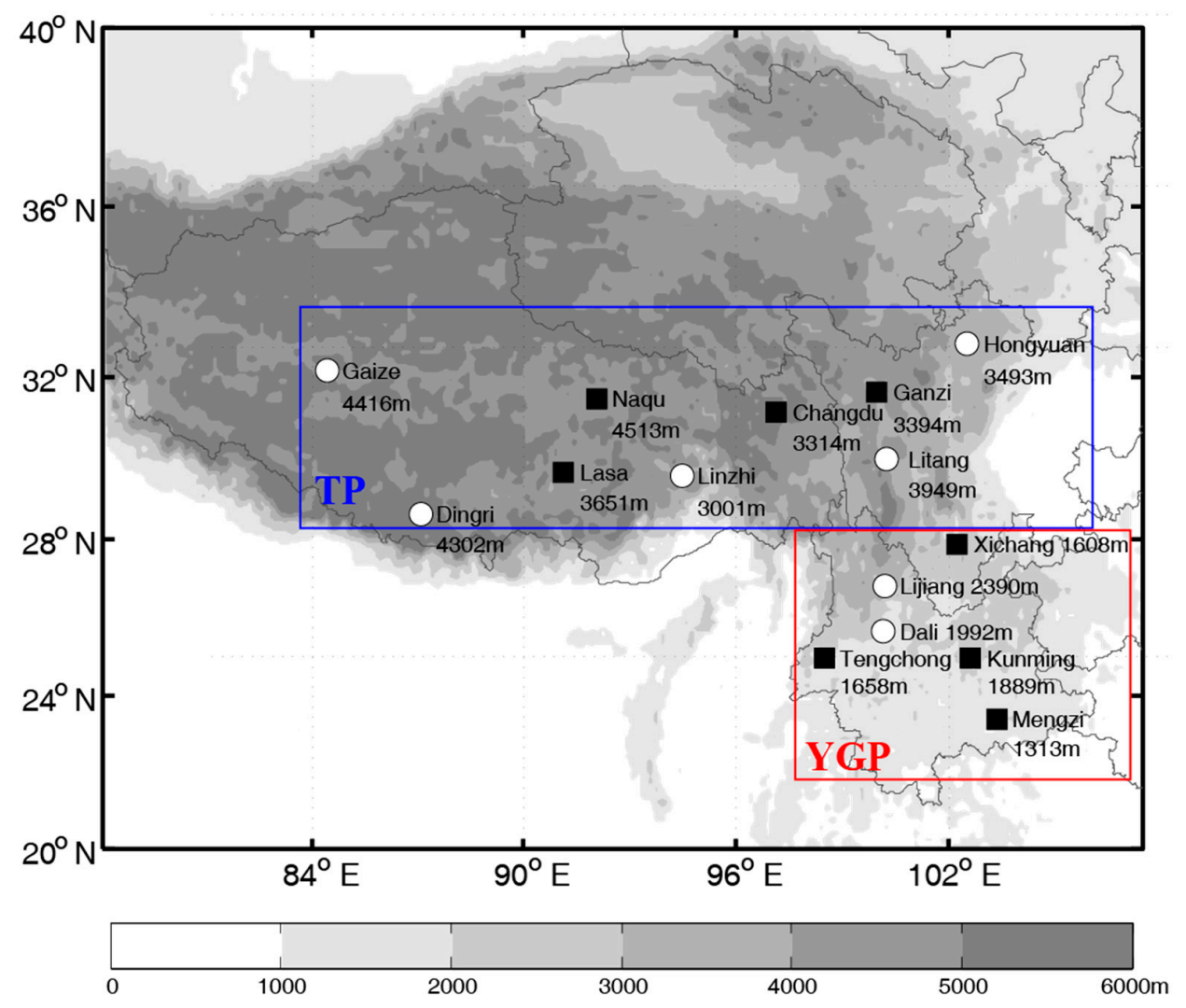

Figure 1. Locations of the independent radiosonde sites over the Tibetan Plateau (TP, blue box) and the Yunnan-Guizhou Plateau (YGP, red box) during the 2008 China-Japan Meteorological Disaster Reduction Cooperation Research Center Project (JICA)/Tibet Project intensive observing period (IOP). Gray shading represents topography. The black squares denote the routine sounding stations, and the white circles denote the added stations.

\section{Data and Methodology}

Three reanalysis datasets-consisting of 20CR, JRA-55, and JRA-55C - are intercompared in this study. 20CR [26] is a reanalysis project jointly conducted by the National Oceanic and Atmospheric Administration's (NOAA) Physical Sciences Laboratory and the Cooperative Institute for Research in Environmental Sciences (CIRES) at the University of Colorado, which applies an ensemble Kalman filter scheme and assimilates only surface pressure observations into NOAA's Global Forecast System. The version used in this study is V2c, with a grid resolution of $75 \mathrm{~km}$, covering 1851 to 2012. JRA-55 [27] is a global atmospheric reanalysis led by the Japan Meteorological Agency (JMA). It uses a 4D-Var data assimilation method to assimilate both conventional and satellite observations. JRA-55 spans 1958 to the present and has $\sim 55 \mathrm{~km}$ of spatial resolution and 60 vertical levels. JRA-55C [28] stems from the same system as JRA-55, with the assimilation of only conventional surface and upper-air observations. It produces a reanalysis dataset, which is more homogeneous and not influenced by variations of the satellite observing systems throughout history.

To evaluate the quality of these three reanalyses, the enhanced independent radiosonde sounding observations recorded during the intensive observing period (IOP) of the JICA/Tibet project from 20 June to 19 July 2018 were used in this study. Sounding observations were gathered every $6 \mathrm{~h}(0000,0600,1200,1800 \mathrm{UTC})$ at 15 locations covering the Tibetan Plateau and the western Yunnan-Guizhou Plateau (Figure 1). There are nine sparsely and highly distributed stations $(>3000 \mathrm{~m}$ ) located on TP, and six relatively closer and lower stations (1300-2400 m) located on YGP. The 0000 and 1200 UTC observations at Naqu, Lasa, Changdu, Ganzi, Xichang, Tengchong, Kunming, and Mengzi, which belong 
to the standard observing network and were assimilated in JRA-55 and JRA-55C, were excluded for completely independent verifications. Four types of radiosondes, these being the GTS1 (Tengchong, Kunming, Hongyuan, Ganzi, Dingri, Xichang, Naqu, Lasa), 59-701 (Mengzi, Linzhi, Changdu), Vaisala RS92 (Gaize, Litang, Dali), and TD2-A digital sonde (Lijiang), were applied for the enhanced sounding observations during the 2008 JICA/Tibet Project. In the World Meteorological Organization (WMO) intercomparison of high-quality radiosonde systems implemented at Yangjiang, China in 2010, GTS1 and Vaisala RS92 had the higher scores of $4.5-5$ for temperature $(<16 \mathrm{~km})$, humidity $\left(\mathrm{T}>-40{ }^{\circ} \mathrm{C}\right)$, wind (troposphere) in the intercomparison of 13 radiosonde systems from nine countries. The score for evaluating operational performance was set to range one to six, but no radiosonde system scored more than five [31]. Bao and Zhang [14] have verified three of them (GTS1, Vaisala RS92, and 59-701) as having high accuracy and good quality and stability; the interinstrument difference between these radiosondes was small in wind speed $(< \pm 0.2 \mathrm{~m} / \mathrm{s})$ and temperature $\left(< \pm 0.2{ }^{\circ} \mathrm{C}\right)$ in the mid-upper troposphere and slightly large in relative humidity $(\sim 10 \%)$ above $-40{ }^{\circ} \mathrm{C}$. The TD2-A radiosondes were also frequently used during that period.

The enhanced sounding observation data provided by the JICA/Tibet team include four quality-controlled conventional above ground variables (wind direction, wind speed, temperature, and dewpoint depression) interpolated to eight standard vertical levels (600, 500, 400, 300, 250, 200, 150, and $100 \mathrm{hPa}$ ) over TP and nine levels (700, 600, 500, 400, 300, 250, 200, 150, and $100 \mathrm{hPa}$ ) over YGP. As in Bao and Zhang [14], we used the wind direction and wind speed to derive the horizontal meridional and zonal winds ( $U$ and V). The specific humidities $(Q)$ were calculated from the temperatures and dewpoint temperatures in accordance with the method used in the European Centre for Medium-Range Weather Forecasts (ECMWF) interim reanalysis (ERA-Interim) forecast model [32,33].

We used the same methods as in Bao and Zhang $[13,14]$ to make a direct comparison between the gridded reanalyses and discrete soundings. Firstly, we interpolated the pressure coordinate reanalysis data to the standard pressure levels at each of the sounding locations at the same synoptic times. Secondly, we rejected the abnormal values under a subjective criterion of the differences between observation and JRA-55 (i.e., if $\Delta U>30 \mathrm{~m} \mathrm{~s}^{-1}$, and/or $\Delta \mathrm{V}>30 \mathrm{~m} \mathrm{~s}^{-1}$, as well as $\Delta \mathrm{T}>20^{\circ} \mathrm{C}$, Q will be rejected when the temperature $\mathrm{T}$ is eliminated). Thirdly, we compared the sounding observations and the three reanalyses in terms of mean, bias, root-mean-square error (RMSE), and spread of the reanalysis-minusobservation (R-O).

\section{Major Findings}

\subsection{Mean Profiles}

Figure 2a,c,e,g (Figure 2b,d,f,h) show the averaged vertical profiles of $U, V, T$, and Q from the independent soundings at TP (YGP) and the three reanalysis products. At a glance, 20CR provided significantly different mean profiles of these above ground variables, with the exception of temperature, as compared to the other reanalyses and soundings. As mentioned in Bao and Zhang (2019), the mean observed zonal winds were predominantly westerlies with a maximum of $\sim 10 \mathrm{~m} / \mathrm{s}$ around $200 \mathrm{hPa}$ over TP (Figure 2a). Meanwhile, the averaged observed zonal winds over YGP were weak westerlies near the ground and easterlies with a maximum of $\sim 14 \mathrm{~m} / \mathrm{s}$ near the tropopause (Figure $2 \mathrm{~b}$ ). The mean observed meridional winds over TP and YGP showed a similar vertical profile, both of them with northerly winds throughout almost all levels except the very weak southerly flows near the ground (Figure 2c,d). JRA-55 and JRA-55C closely followed well those averaged horizontal winds over TP and YGP. The mean horizontal winds of 20CR differed notably from the verifying observed sounding mean and the other reanalyses. 20CR significantly undervalues the zonal winds throughout the vertical profile, overestimates (undervalues) the meridional winds near the tropopause over TP and YGP (in the mid-troposphere (250-700 hPa) over YGP) (Figure 2a-d). The mean temperature profiles and the mean specific humidity profiles of each reanalysis and soundings all show expected decreases 
with increasing height (Figure 2e-h). The mean temperature profiles from the sounding and the three reanalysis products were hardly distinguishable from each other. Therefore, these reanalyses represent very well the mean dry, static stability (Figure 2e,f), as also found in Bao and Zhang $[13,14]$. The mean specific humidity profiles of JRA-55 and JRA-55C nearly overlapped with the mean soundings over TP and YGP, but the mean specific humidity from 20CR as wetter (larger) than the soundings observed over TP and YGP (Figure 2g,h).
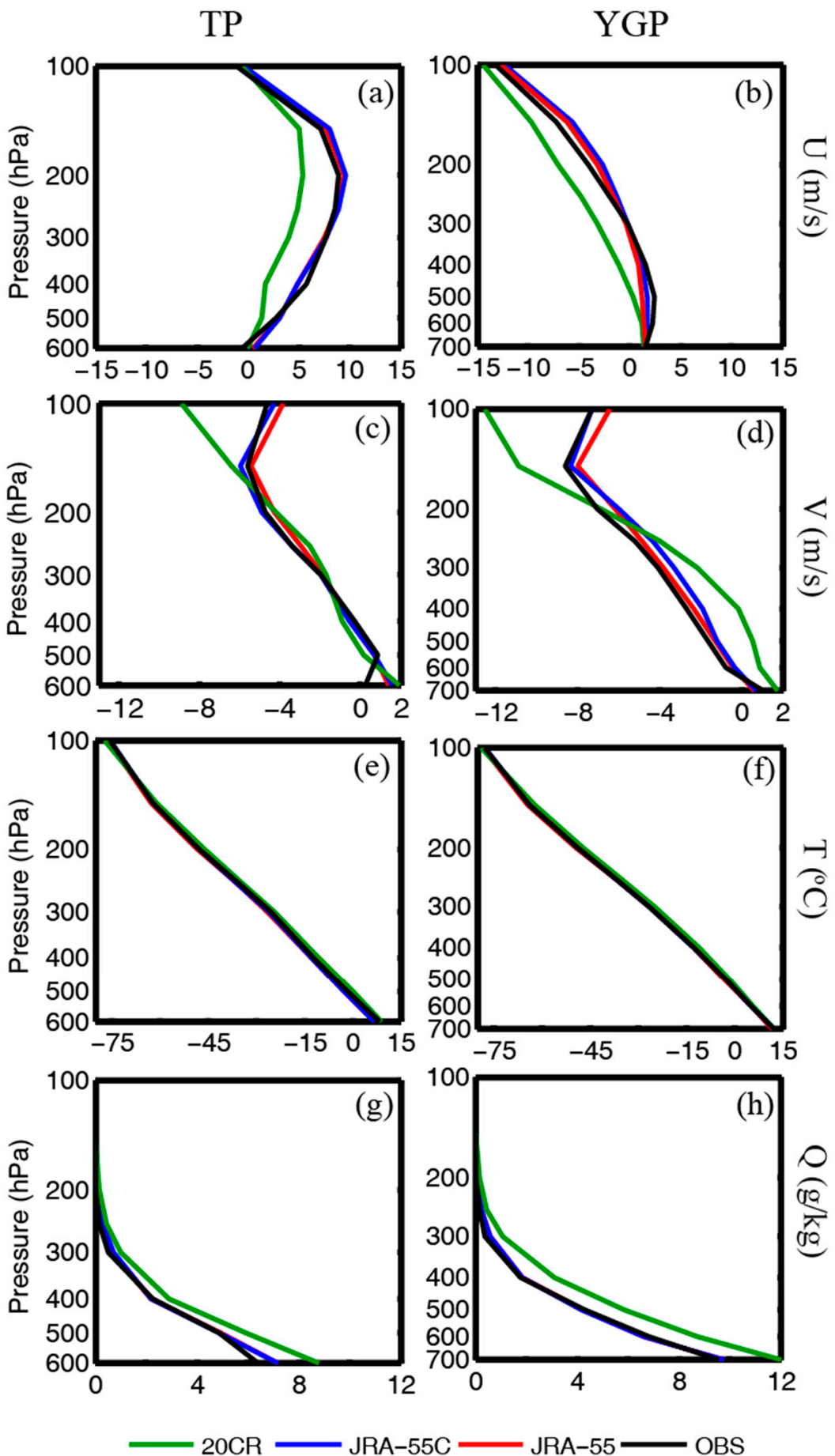

Figure 2. Vertical profiles of mean values for $(\mathbf{a}, \mathbf{b})$ meridional winds (U), (c,d) zonal winds (V), $(\mathbf{e}, \mathbf{f})$ temperature $(\mathrm{T})$, and $(\mathbf{g}, \mathbf{h})$ humidity $(\mathrm{Q})$ averaged over the independent soundings and three reanalysis datasets at (left) TP and at (right) YGP during the 2008 JICA/Tibet Project IOP. 


\subsection{Mean Biases and RMSEs}

In order to quantitatively assess the quality and utility of these reanalysis products, the mean biases and RMSEs between each reanalysis and the observed soundings (R-O) were calculated (Figures 3 and 4 ).
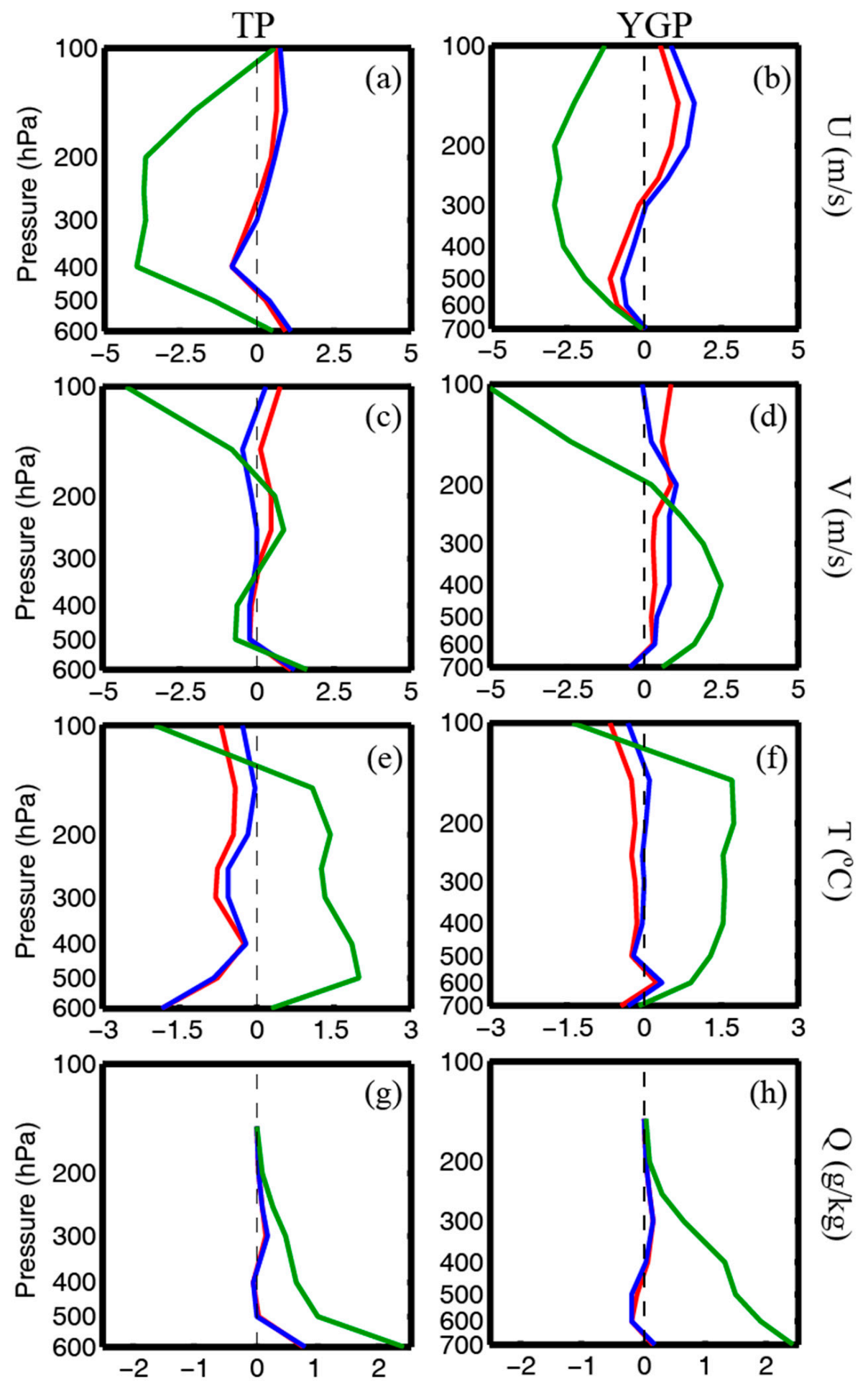

Figure 3. Vertical profiles of the mean biases of $(\mathbf{a}, \mathbf{b}) \mathrm{U},(\mathbf{c}, \mathbf{d}) \mathrm{V},(\mathbf{e}, \mathbf{f}) \mathrm{T}$, and $(\mathbf{g}, \mathbf{h}) \mathrm{Q}$ averaged over the independent soundings at (left) TP and at (right) YGP, respectively, for each reanalysis against the observations during the 2008 JICA/Tibet Project IOP. 

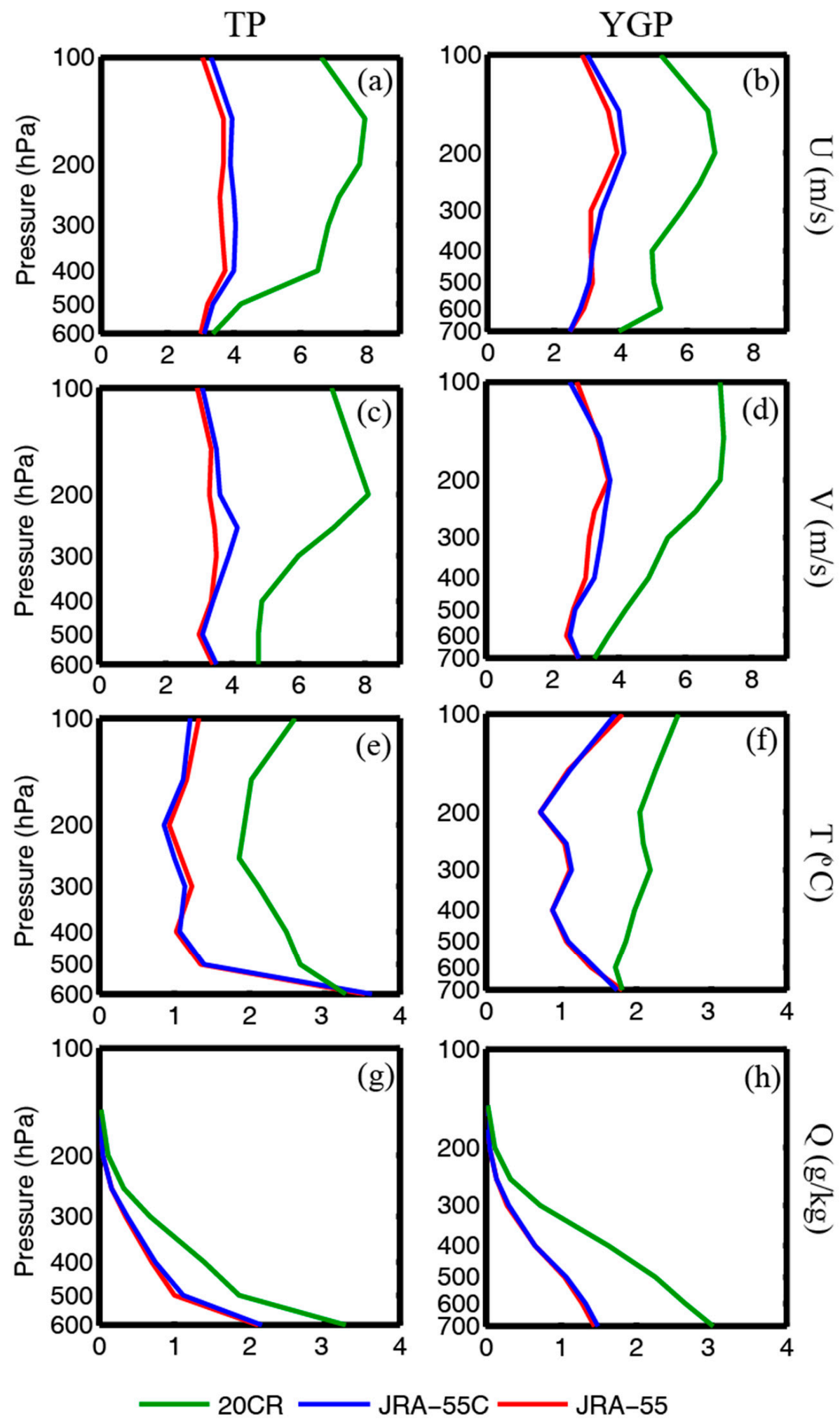

Figure 4. Vertical profiles of the mean RMSEs of (a) (b) U, (c) (d) V, (e) (f) T, and (g) (h) Q averaged over the independent soundings at (left) TP and at (right) YGP, respectively, for each reanalysis against the observations during the 2008 JICA/Tibet Project IOP. 


\subsubsection{Horizontal Wind}

Not surprisingly, 20CR had the largest mean meridional wind biases. It underestimated the westerlies at almost all levels, with a maximum bias of $\sim-4 \mathrm{~m} / \mathrm{s}$ between $200-400 \mathrm{hPa}$ over TP and a relatively smaller maximum bias of $\sim 3 \mathrm{~m} / \mathrm{s}$ between 200-300 hPa over YGP. The mean meridional wind biases for JRA-55C and JRA-55 were rather small and mostly within $1 \mathrm{~m} / \mathrm{s}$ over TP, and $2 \mathrm{~m} / \mathrm{s}$ over YGP throughout the vertical column (Figure $3 a, b)$. The zonal wind biases were also the largest among the three reanalysis products over both regions, with the bias over YGP being larger. The $20 \mathrm{CR}$ reanalysis over TP had positive biases of $\sim 2 \mathrm{~m} / \mathrm{s}$ near the ground and peaked at about $1.5 \mathrm{~m} / \mathrm{s}$ between $200-350 \mathrm{hPa}$, and negative biases of $\sim-1 \mathrm{~m} / \mathrm{s}$ between $400-500 \mathrm{hPa}$ and up to $-4 \mathrm{~m} / \mathrm{s}$ near $100 \mathrm{hPa}$. The zonal wind biases were reduced at all levels for JRA-55C and JRA-55, with the largest decrease occurring near $100 \mathrm{hPa}$ from $-4 \mathrm{~m} / \mathrm{s}$ in $20 \mathrm{CR}$ to a small positive bias $(<0.5 \mathrm{~m} / \mathrm{s})$ in JRA-55 and near zero in JRA-55C (Figure 3c). 20CR over YGP had a small positive zonal wind bias below $200 \mathrm{hPa}$ with a maximum bias of $\sim 2.5 \mathrm{~m} / \mathrm{s}$ around $400 \mathrm{hPa}$ and negative biases above $400 \mathrm{hPa}$ up to $-5 \mathrm{~m} / \mathrm{s}$. JRA-55 and JRA-55C over YGP all had small positive zonal wind biases $(<1.5 \mathrm{~m} / \mathrm{s})$ throughout almost all levels, with less than half the zonal wind bias of 20CR (Figure 3d). Furthermore, the difference in V biases between JRA-55 and JRA-55C over YG was larger than that over TP. The zonal wind biases for JRA-55 and JRA-55C were similar over TP below $300 \mathrm{hPa}$, but negative and positive, respectively, above that level (Figure 3c). JRA-55 and JRA-55C had negative (positive) zonal wind biases below (above) $300 \mathrm{hPa}$, whereas the zonal wind biases from JRA-55 was slightly larger (smaller) than JRA-55C, below (above) $300 \mathrm{hPa}$ over YGP (Figure 3d).

The obvious differences in the meridional and zonal wind between $20 \mathrm{CR}$ and two other reanalyses were also shown through RMSE (R-O) (Figure 4a-d). 20CR had nearly twice the RMSE for meridional wind compared to JRA-55 and JRA-55C. The meridional wind RMSE of 20CR peaked at $8 \mathrm{~m} / \mathrm{s}$ at $150 \mathrm{hPa}$ over TP and about $7 \mathrm{~m} / \mathrm{s}$ at $150-200 \mathrm{hPa}$ over YGP, whereas the meridional wind RMSEs of JRA-55 and JRA-55C were $\sim 3 \mathrm{~m} / \mathrm{s}$, with little variation over TP and YGP. The zonal wind RMSEs showed similarities with the meridional wind RMSEs. JRA-55 had slightly smaller meridional and zonal wind RMSEs than JRA-55C, with the relatively obvious difference between 150-400 hPa. On the whole, 20CR had the largest RMSEs for horizontal winds, whereas JRA-55 had the smallest RMSEs, with tiny differences compared to JRA-55C

\subsubsection{Temperature}

The largest temperature biases over TP and YGP were also seen for 20CR (Figure 3e,f). $20 \mathrm{CR}$ has a positive (warm) bias compared to sounding observations below $150 \mathrm{hPa}$, where the positive (warm) was around $2{ }^{\circ} \mathrm{C}\left(1.5^{\circ} \mathrm{C}\right)$ over TP (YGP), and a negative (cold) bias of around $-2{ }^{\circ} \mathrm{C}\left(-1.5^{\circ} \mathrm{C}\right)$ near $100 \mathrm{hPa}$. JRA-55C had the smallest negative (cold) bias over $\mathrm{TP}$, which was about $-2{ }^{\circ} \mathrm{C}$ near the surface and which generally decreased with height, and was almost negligible around $400 \mathrm{hPa}$ and above $200 \mathrm{hPa}$. JRA- 55 had a similar bias with JRA-55C, but was slightly larger than JRA-55C above $400 \mathrm{hPa}$. The T biases over YGP showed similar features to those over TP, but all three reanalyses had smaller bias below $500 \mathrm{hPa}$, except near the surface where the bias was around zero (Figure 3e,f).

The temperature RMSEs of 20CR and the two other reanalyses showed great differences over TP and YGP (Figure 4e,f). Clearly, the largest was for 20CR, from a maximum of $\sim 3.2{ }^{\circ} \mathrm{C}$ at $600 \mathrm{hPa}$ to a valley value of $\sim{ }^{\circ} \mathrm{C}$ around $300 \mathrm{hPa}$, and then rise to $\sim{ }^{\circ} \mathrm{C}$ at $100 \mathrm{hPa}$. The smaller overall RMSEs were for JRA-55 and JRA-55C, both of which were very close to each other. The RMSEs were $\sim 4{ }^{\circ} \mathrm{C}$ near the surface and around $1.2^{\circ} \mathrm{C}$ above $500 \mathrm{hPa}$ over TP. 20CR over YGP also had the largest RMSE, from $\sim 1.8^{\circ} \mathrm{C}$ at $700 \mathrm{hPa}$, increasing to $2.6^{\circ} \mathrm{C}$ at the tropopause. The temperature RMSEs of JRA-55 and JRA-55C were only one-third to one-half of that of 20CR.

Overall, these temperature biases and RMSEs largely diminished from 20CR (assimilating surface pressure only) to JRA-55C (assimilating conventional data). Although assimilating 
both conventional and satellite data, JRA- 55 did not show a notable reduction, but it showed slightly larger biases above $400 \mathrm{hPa}$ than JRA-55C. Comparing radiosonde temperatures in China with the temperatures from eight reanalysis datasets, Guo et al. [34] also found that 20CR had obviously higher temperatures than observations at almost all vertical levels except $200 \mathrm{hPa}$, and significant differences with other reanalyses assimilating conventional and satellite data.

\subsubsection{Specific Humidity}

The mean biases in specific humidity $(\mathrm{Q})$ also showed huge differences between $20 \mathrm{CR}$ and the two other reanalyses, whereas JRA-55 and JRA-55C agree closely with each other (Figure 3g,h). 20CR had the overall largest bias in moisture content over TP and YGP. The bias in 20CR had a positive maximum of $\sim 2.2 \mathrm{~g} / \mathrm{kg}$ at $600 \mathrm{hPa}(700 \mathrm{hPa})$ and decreased with height to almost zero above $200 \mathrm{hPa}$ over TP (YGP). The mean Q biases in JRA-55 and JRA-55C over TP were moist (positive) overall, with the maximum value of $\sim 0.9 \mathrm{~g} / \mathrm{kg}$ near the surface and near-zero above $500 \mathrm{hPa}$. The mean Q biases in JRA-55 and JRA-55C over YGP varied between $-0.2 \mathrm{~g} / \mathrm{kg}$ and $0.2 \mathrm{~g} / \mathrm{kg}$. In contrast with the maximum bias over TP, the biases near the surface in JRA-55 and JRA-55C was almost negligible near the surface, indicating that JRA- 55 and JRA-55C had larger biases of specific humidity over the higher TP.

Similar to wind and temperature, specific humidity over TP and YGP also showed greatly different RMSE profiles between 20CR and the two others, whereas the RMSE profiles were similar in JRA-55 and JRA-55C (Figure 4g,h). 20CR had the largest RMSE of specific humidity, and its maximum value was $\sim 3.2(3) \mathrm{g} / \mathrm{kg}$ near the surface, which was nearly 1.5 times that of JRA- 55 and JRA-55C over TP (YGP). Note that the positive maxima in JRA-55 and JRA-55C near the surface over TP $(2.1 \mathrm{~g} / \mathrm{kg})$ were larger than that over YGP $(1.5 \mathrm{~g} / \mathrm{kg})$, which means that these analyses were not consistent over the different regions with different heights and different observational data densities.

\subsection{Variations of Uncertainty and Bias}

The reanalysis-to-reanalysis variations in bias spreads for TP and YGP are summarized in Figure 5. The results further support the evidence of the prominent decrease in bias spread from 20CR to JRA-55 and JRA-55C. The zonal and meridional wind biases for 20CR over TP and YGP were significantly greater than those for JRA-55C and JRA-55. Such differences were more significant in the upper troposphere, where the span of wind bias for JRA-55C and JRA-55 was cut to almost half of that for 20CR (Figure 5a,b,e,f). For temperature, the bias spreads presented a relatively small reduction in the trend from $20 \mathrm{CR}$ to JRA-55 and JRA-55C (Figure $5 \mathrm{c}, \mathrm{g}$ ). The temperature biases of 20CR were mostly positive between $150-500 \mathrm{hPa}(150-600 \mathrm{hPa})$ over TP (YGP). Almost $80 \%$ of the temperature biases of JRA-55C and JRA-55 were negative at almost all altitude ranges over TP, whereas these temperature biases showed a more normal distribution over YGP. For specific humidity, more than $85 \%$ of the humidity biases of $20 \mathrm{CR}$ were more than zero over TP and YGP. By comparison, the specific humidity biases of JRA-55 and JRA-55C had a smaller span and were near to a normal distribution. Moreover, the bias spreads of temperature and specific humidity near the surface were the maximum throughout the vertical column over $\mathrm{TP}$, which was significantly greater than that over YGP (Figure 5d,h). 

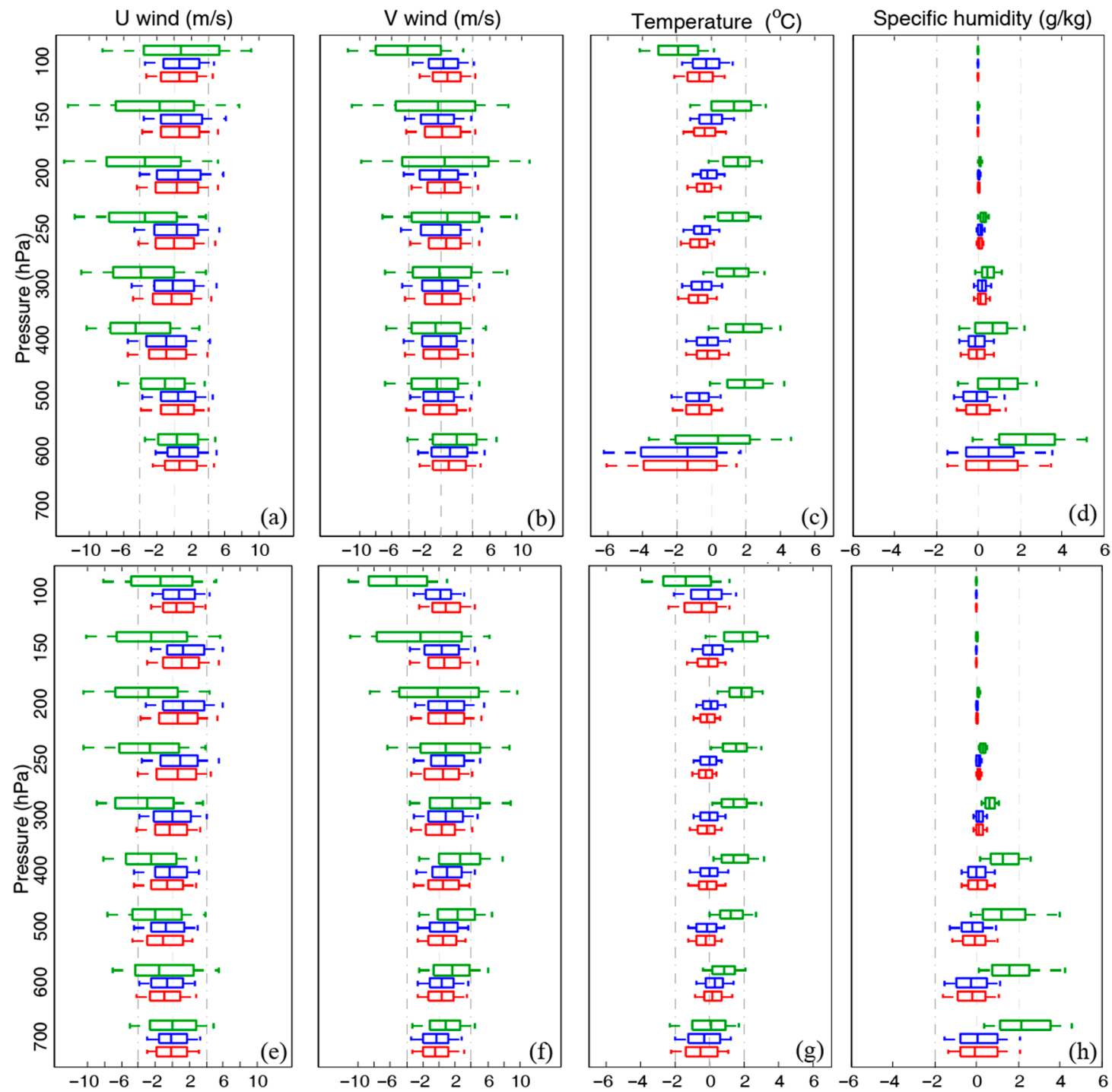

Figure 5. Box-and-whisker plots of $U, V, T$, and $Q$ bias for all independent soundings over TP (a-d) and YGP (e--h) for 20thCR (green), JRA-55C (blue), and JRA-55 (red), verified against observations (reanalysis-minus-observation (R-O)) during the 2008 JICA/Tibet Project IOP. The central mark is the median, the edges of the box are the 25th and 75th percentiles, and the whiskers extend to the 10th and 90th percentiles.

Evidently, the 20CR reanalysis (without conventional and satellite data assimilation) had the largest analysis uncertainty, according to the bias spreads of these four aboveground variables, then the two other reanalysis methods. The differences between JRA-55C and JRA-55 were rather small for the quality of these variables, although the satellite data was also used in JRA-55. He et al. [35] have developed a method of regional reanalysis over TP based on an ensemble-based data assimilation system and found prototype reanalysis assimilating non-radiance observations had better accuracy in analyzing atmospheric humidity than the leading modern atmospheric reanalyses-the fifth generation ECMWF atmospheric reanalysis of the global climate (ERA5) and the ERA-Interim analysis.

The significant effect of conventional observations on a multi-year reanalysis (the Modern-Era Retrospective analysis for Research and Applications, Version 2 (MERRA-2)) was also noted in some recent studies which employed the forecast sensitivity-based observation impact (FSOI) technique [36,37]. Diniz and Todling [36] indicated that conventional observations played a major role in reducing forecast errors throughout the nearly 40-year reanalysis period. Diniz et al. [36] applied the same FSOI technique to MERRA-2 over the 
Amazon basin and found that more than half of the forecast error reduction was related to conventional observations after 1999. Excepting the differences in input observations, differences in the forecast models and data assimilation methods also affect the quality of reanalyses. These differences were much smaller than those observed between 20CR and JRA-55 in 2008. This is an example showing that the differences in forecast models and data assimilation methods are minor in impact on the performance of reanalyses as compared to differences of assimilating only surface observations and of also assimilating upper-air observations. Moreover, 20CR exhibited a similar performance with the older generation reanalyses (prior to 2010) of the National Centers for Environmental Prediction/National Center for Atmospheric Research (NCEP/NCAR) and the Japan Meteorological Agency Climate Data Assimilation System (JCDAS) in the Antarctic Peninsula region [37]. However, compared with the other new-generation reanalyses, 20CR has obviously larger biases and larger RMSE for temperature, specific humidity, and wind in the Antarctic Peninsula region [38].

\section{Conclusions}

In this study, we evaluated and compared three reanalysis products that assimilated different observations, namely, 20CR (using only surface pressure), JRA-55C (using only conventional observations), and JRA-55 (using conventional and satellite observations), by validating them against independent sounding observations from the 2008 JICA/Tibet project. Our purpose was to determine the influence of the assimilation of observed data (especially conventional data) on the quality of reanalysis products in the troposphere over the Tibetan Plateau and the western Yunnan-Guizhou Plateau. Secondly, in this study, we explored the degrees to which these reanalyses differently impacted the atmospheric variables over the high Tibetan Plateau (>3000 m) and the relatively low Yunnan Guizhou Plateau (about 1300-2400 m).

It was found that 20CR, with no use of conventional and satellite observation, had the largest mean biases and uncertainties for the horizontal wind, temperature, and specific humidity over TP and YGP. 20CR had significantly overvalued temperatures and specific humidities throughout almost all levels, along with undervalued westerlies and upperlevel easterlies. For JRA-55C, assimilating conventional surface and upper-air observations, and JRA-55, assimilating conventional and satellite data, the mean biases and RMSEs of these aboveground variables were generally cut down to $50-70 \%$ of those found in 20CR. The bias spreads had a smaller span and neared a normal distribution compared to 20CR. However, although the RMSEs of horizontal winds in JRA-55 were slightly smaller than those in JRA-55C, a notable decreasing trend for the mean biases and RMSEs of these variables was not present from JRA-55C to JRA-55, although satellite data was also included in JRA-55. The biases between JRA-55 and JRA-55C had no significant differences, especially for temperature and humidity. This shows that the assimilation of conventional observation data has a significant effect on quality improvements for reanalysis products in the troposphere over these data-sparse plateaus. Adding satellite data assimilation to conventional data assimilation has a weak positive impact on the upper-level horizontal winds but has a negligible impact on temperature and specific humidity. However, this does not mean that the effect of satellite data assimilation by itself is small; the result will be more reliable if the reanalysis data assimilated only satellite observations added into the comparison. In addition, the reanalyses showed similar overall performances over TP and YGP. In general, JRA-55 and JRA-55C over both TP and YGP were able to reproduce well the vertical profiles of the mean horizontal wind, temperature, and specific humidity against the verifying radiosonde observations with small mean biases, although 20CR had up to twice the biases of JRA-55 and JRA-55C for these variables. However, compared to YGP, the temperature and specific humidity near the surface in JRA-55 and JRA-55C showed greater uncertainties by having higher RMSEs and larger spans of bias spread. This is probably due to the fact that the near-surface observational data for TP were more sparse than those for YGP. 
Author Contributions: Data curation, Y.Z. and X.B.; Formal analysis, X.B.; Investigation, X.B.; Methodology, F.Z. and X.B.; Validation, Y.C.; Writing—original draft, X.B.; Writing—review \& editing, X.B. All authors have read and agreed to the published version of the manuscript.

Funding: This study was supported by the National Natural Science Foundation of China (Grant No. 41775002), National Key Research and Development Program of China (Grant No. 2018YFC1505705).

Acknowledgments: We are grateful to Xiangde $\mathrm{Xu}$ at the Chinese Academy of Meteorological Sciences for providing us the quality-controlled radiosonde observations collected during the intensive observation periods of the JICA/Tibet Project. The reanalysis datasets were downloaded directly from the data archives at the National Center for Atmospheric Research.

Conflicts of Interest: The authors declare no conflict of interest.

\section{References}

1. Ye, D. Some characteristics of the summer circulation over the Qinghai-Xizang (Tibet) Plateau and its neighborhood. Bull. Am. Meteor. Soc. 1981, 62, 14-19. [CrossRef]

2. Ye, D.; $\mathrm{Wu}, \mathrm{G}$. The role of the heat source of the Tibetan Plateau in the general circulation. Meteor. Atmos. Phys. 1998, 67, 181-198. [CrossRef]

3. Molnar, P.; Boos, W.R.; Battisti, D.S. Orographic controls on climate and paleoclimate of Asia: Thermal and mechanical roles for the Tibetan Plateau. Annu. Rev. Earth Planet. Sci. 2010, 38, 77-102. [CrossRef]

4. Bao, X.; Zhang, F.; Sun, J. Diurnal variations of warm season precipitation east of the Tibetan Plateau over China. Mon. Weather Rev. 2011, 139, 2790-2810. [CrossRef]

5. Si, D.; Ding, Y.Y. Decadal change in the correlation pattern between the Tibetan Plateau winter snow and the East Asian summer precipitation during 1979-2011. J. Clim. 2013, 26, 7622-7634. [CrossRef]

6. Hu, L.; Deng, D.; Xu, X.; Zhao, P. The regional differences of Tibetan convective systems in boreal summer. J. Geophys. Res. Atmos. 2017, 122, 7289-7299. [CrossRef]

7. Shi, Z.; Sha, Y.; Liu, Y.X. Effect of Yunnan-Guizhou topography at the southeastern Tibetan Plateau on the Indian monsoon. J. Clim. 2017, 30, 1259-1272. [CrossRef]

8. Shi, Z.; Sha, Y.; Liu, X.; Xie, X.; Li, X. Effect of marginal topography around the Tibetan Plateau on the evolution of central Asian arid climate: Yunnan-Guizhou and Mongolian Plateaux as examples. Clim. Dyn. 2019. [CrossRef]

9. Feng, X.; Liu, C.; Rasmussen, R.; Fan, G. A 10-yr climatology of Tibetan Plateau vortices with NCEP Climate Forecast System Reanalysis. J. Appl. Meteor. Climatol. 2014, 53, 34-46. [CrossRef]

10. Gerlitz, L.; Conrad, O.; Thomas, A.; Böhner, J. Warming patterns over the Tibetan Plateau and adjacent lowlands derived from elevation-and bias-corrected ERA-Interim data. Clim. Res. 2014, 58, 235-246. [CrossRef]

11. Gao, Y.; Xu, J.; Chen, D. Evaluation of WRF mesoscale climate simulations over the Tibetan Plateau during 1979-2011. J. Clim. 2015, 28, 2823-2841. [CrossRef]

12. Cuo, L.; Zhang, Y. Spatial patterns of wet season precipitation vertical gradients on the Tibetan Plateau and the surroundings. Sci. Rep. 2017, 7, 5057. [CrossRef] [PubMed]

13. Bao, X.; Zhang, F. Evaluation of NCEP-CFSR, NCEP-NCAR, ERA-Interim, and ERA-40 reanalysis datasets against independent sounding observations over the Tibetan Plateau. J. Clim. 2013, 26, 206-214. [CrossRef]

14. Bao, X.; Zhang, F. How Accurate Are Modern Atmospheric Reanalyses for the Data-Sparse Tibetan Plateau Region? J. Clim. 2019, 32, 7153-7172. [CrossRef]

15. Lindsay, R.W.; Wensnahan, M.; Schweiger, A.; Zhang, J. Evaluation of seven different atmospheric reanalysis products in the Arctic. J. Clim. 2014, 27, 2588-2606. [CrossRef]

16. Fujiwara, M.; Wright, J.S.; Manney, G.L.; Gray, L.J.; Anstey, J.; Birner, T.; Homeyer, C.R. Introduction to the SPARC Reanalysis Intercomparison Project (S-RIP) and overview of the reanalysis systems. Atmos. Chem. Phys. 2017, 17, 1417-1452. [CrossRef]

17. Kalnay, E.; Kanamitsu, M.; Kistler, R.; Collins, W.; Deaven, D.; Gandin, L.; Zhu, Y. The NCEP/NCAR 40-Year Reanalysis Project. Bull. Am. Meteorol. Soc. 1996, 77, 437-471. [CrossRef]

18. Bosilovich, M.G.; Robertson, F.R.; Chen, J. Global Energy and Water Budgets in MERRA. J. Clim. 2011, 24, 5721-5739. [CrossRef]

19. Robertson, F.R.; Bosilovich, M.G.; Chen, J.; Miller, T.L. The Effect of Satellite Observing System Changes on MERRA Water and Energy Fluxes. J. Clim. 2011, 24, 5197-5217. [CrossRef]

20. Robertson, F.R.; Bosilovich, M.G.; Roberts, J.B.; Reichle, R.H.; Adler, R.; Ricciardulli, L.; Berg, W.; Huffman, G.J. Consistency of Estimated Global Water Cycle Variations over the Satellite Era. J. Clim. 2014, 27, 6135-6154. [CrossRef]

21. Wang, A.; Zeng, X. Evaluation of multireanalysis products with in situ observations over the Tibetan Plateau. J. Geophys. Res. 2012, 117, D05102. [CrossRef]

22. Zhao, T.; Wang, J.; Dai, A. Evaluation of atmospheric precipitable water from reanalysis products using homogenized radiosonde observations. J. Geophys. Res. 2015, 120. [CrossRef]

23. Dong, Y.; Li, G.; Yuan, M.; Xie, X. Evaluation of Five Grid Datasets against Radiosonde Data over the Eastern and Downstream Regions of the Tibetan Plateau in Summer. Atmosphere 2017, 8, 56. [CrossRef] 
24. Long, C.S.; Fujiwara, M.; Davis, S.; Mitchell, D.M.; Wright, C.J. Climatology and interannual variability of dynamic variables in multiple reanalyses evaluated by the SPARC Reanalysis Intercomparison Project (S-RIP). Atmos. Chem. Phys. 2017, 17, 14593-14629. [CrossRef]

25. Davis, S.M.; Hegglin, M.I.; Fujiwara, M.; Dragani, R.; Harada, Y.; Kobayashi, C.; Tegtmeier, S. Assessment of upper tropospheric and stratospheric water vapour and ozone in reanalyses as part of S-RIP. Atmos. Chem. Phys. 2017, 17, 12743-12778. [CrossRef]

26. Kobayashi, S.; Ota, Y.; Harada, Y.; Ebita, A.; Moriya, M.; Onoda, H.; Onogi, K.; Kamahori, H.; Kobayashi, C.; Endo, H.; et al. The JRA-55 Reanalysis: General Specifications and Basic Characteristics. J. Meteorol. Soc. Jpn. 2015, 93, 5-48. [CrossRef]

27. Compo, G.P.; Whitaker, J.S.; Sardeshmukh, P.D.; Matsui, N.; Allan, R.J.; Yin, X.; Brönnimann, S. The Twentieth Century Reanalysis Project. Q. J. R. Meteorol. Soc. 2011, 137, 1-28. [CrossRef]

28. Kobayashi, C.; Endo, H.; Ota, Y.; Kobayashi, S.; Onoda, H.; Harada, Y.; Onogi, K.; Kamahori, H. Preliminary results of the JRA-55C, an atmospheric reanalysis assimilating conventional observations only. Sola 2014, 10, 78-82. [CrossRef]

29. Chen, G.; Iwasaki, T.; Qin, H.; Sha, W. Evaluation of the Warm-Season Diurnal Variability over East Asia in Recent Reanalyses JRA-55, ERA-Interim, NCEP CFSR, and NASA MERRA. J. Clim. 2014, 27, 5517-5537. [CrossRef]

30. Zhang, R.; Xu, X.; Koike, T.; Ma, Y.; Yang, K. A China-Japan cooperative JICA atmospheric observing network over the Tibetan Plateau (JICA/Tibet Project): An overview. J. Meteorol. Soc. Jpn. 2012, 90C, 1-16. [CrossRef]

31. NaSh, J.; Oakley, T.; Vomel, H.; Wei, L. WMO Intercomparison of High Quality Radiosonds Systems, Yangjiang, China, 12 July-3 August 2010; Instruments and Observing Methods Report No. 107; World Meteorological Organization: Geneva, Switzerland, 2011; 248p

32. Simmons, A.J.; Untch, A.; Jakob, C.; Kållberg, P.; Undén, P. Stratospheric water vapour and tropical tropopause temperatures in ECMWF analyses and multi-year simulations. Q. J. R. Meteorol. Soc. 1999, 125, 353-386. [CrossRef]

33. Dee, D.P.; Uppala, S.M.; Simmons, A.J.; Berrisford, P.; Poli, P.; Kobayashi, S.; Bechtold, P. The ERA-Interim reanalysis: Configuration and performance of the data assimilation system. Q. J. R. Meteorol. Soc. 2011, 137, 553-597. [CrossRef]

34. Guo, Y.; Zhang, S.; Yan, J.; Chen, Z.; Xin, R. A comparison of atmospheric temperature over China between radiosonde observations and multiple reanalysis datasets. J. Meteor. Res. 2016, 30, 242-257. [CrossRef]

35. He, J.; Zhang, F.; Chen, X.; Bao, X.; Chen, D.; Kim, H.M.; Ou, T. Development and evaluation of an ensemble-based data assimilation system for regional reanalysis over the Tibetan Plateau and surrounding regions. J. Adv. Modeling Earth Syst. 2019, 11, 2503-2522. [CrossRef]

36. Diniz, F.L.R.; Todling, R. Assessing the impact of observations in a multi-year reanalysis. Q. J. R. Meteorol. Soc. 2019, 146, 724-747. [CrossRef]

37. Diniz, F.L.R.; Todling, R.; Herdies, D.L. A brief assessment of the impact of nearly 40 years of assimilated observations over the Amazon basin. Earth Space Sci. 2020, 7, e2019EA000779. [CrossRef]

38. Nygård, T.; Vihma, T.; Birnbaum, G.; Hartmann, J.; King, J.; Lachlan-Cope, T.; Ladkin, L.; Lüpkes, C.; Weissc, A. Validation of eight atmospheric reanalyses in the Antarctic Peninsula region. Q. J. R. Meteorol. Soc. 2016, 142, 684-692. [CrossRef] 